\title{
Rendimento, composição e análise sensorial do queijo minas frescal fabricado com leite de vacas mestiças alimentadas com diferentes volumosos ${ }^{1}$
}

\author{
Susi Cristina dos Santos Guimarães Martins ${ }^{2}$, Vicente Ribeiro Rocha Júnior ${ }^{2}$, Luciana \\ Albuquerque Caldeira ${ }^{2}$, Sidnei Tavares dos Reis ${ }^{2}$, Isabella Coutinho Barros ${ }^{2}$, José Aparecido \\ de Oliveira ${ }^{3}$, Jânio Ferreira dos Santos ${ }^{3}$, Geanderson Walder Vieira Silva ${ }^{2}$ \\ ${ }^{1}$ BNB/Fundeci. \\ 2 UNIMONTES \\ ${ }^{3}$ IFNMG - Campus Salinas.
}

RESUMO - Objetivou-se com este trabalho avaliar a qualidade físico-química e sensorial e o perfil de ácidos graxos do queijo minas frescal produzido com o leite de vacas mestiças alimentadas com dietas contendo quatro volumosos: canade-açúcar, silagem de sorgo, silagem de girassol e pastagem de Panicum maximum cv. Tanzânia. Foram avaliados o rendimento, a composição físico-química e o perfil de ácidos graxos. Também foi realizada a análise sensorial do queijo minas frescal e da composição físico-química do leite. Utilizaram-se oito vacas mestiças 1/2 Holandês/Gir, com período de lactação de $180 \pm 12$ dias, distribuídas em dois quadrados latinos $4 \times 4$, com quatro animais, quatro dietas e quatro períodos. Os períodos foram de 18 dias, sendo 15 dias de adaptação e três dias de coletas de dados. Após o processamento do queijo, foi feita análise microbiológica, físico-química e posteriormente análise sensorial. Amostras do queijo foram congeladas e analisadas quanto ao perfil de ácidos graxos. O teor de gordura do queijo foi maior para as dietas com cana-de-açúcar e silagem de girassol em relação à silagem de sorgo e ao pasto de Panicum maximum cv. Tanzânia, que não diferiram entre si. O queijo produzido a partir do leite de vacas alimentadas com silagem de girassol apresentou melhor perfil de ácidos graxos e índices de qualidade nutricional, maior proporção e melhor perfil de ácidos graxos insaturados. O rendimento do queijo foi igual para todas as dietas, independentemente do volumoso utilizado em sua composição. O queijo produzido com o leite de vacas alimentadas com silagem de girassol tem maior preferência pelos julgadores no teste de análise sensorial, especialmente quanto ao atributo aparência.

Palavras-chave: dietas, qualidade nutricional, perfil de ácidos graxos

\section{Yield, composition and sensory analysis of Minas cheese made with milk from crossbred cows fed different roughages}

\begin{abstract}
The objective of this study was to evaluate the physical-chemical and sensory quality and fatty acid profile of Minas cheese produced from milk from crossbred cows fed diets with four roughages (sugar cane, sorghum silage, sunflower silage and pasture of Panicum maximum cv. Tanzania). Yield, physical-chemical composition, fatty acid profile and sensory analysis of Minas cheese, as well as the physical-chemical composition of milk were analyzed. For the experiment, eight $1 / 2$ Holstein/Gir crossbred cows, with lactation period of $180 \pm 12$ days were distributed in two $4 \times 4$ latin squares (four animals, four diets and four periods). The experimental periods had a duration of 18 days: 15 days of adaptation and three days of data collection. After cheese processing microbiological, physical-chemical and sensory analysis were done. Cheese samples were frozen and analyzed for fatty acid profile. The fat content of cheese was higher for diets with sugar cane and sunflower silage compared with sorghum silage and pasture of Panicum maximum cv. Tanzania. Cheese produced from milk from cows fed sunflower silage had superior fatty acid composition and nutritional quality indexes, and better profile and higher proportion of unsaturated fatty acids. Cheese yield did not differ between diets containing different roughages. Cheese produced from milk from cows fed a diet with sunflower silage presents higher preference at the sensory analysis test, especially regarding the attribute appearance.
\end{abstract}

Key Words: diet, fatty acid profile, nutritional quality 


\section{Introdução}

O queijo minas frescal é o terceiro queijo mais produzido no Brasil e seu processamento pode ser uma alternativa para aumentar a renda do produtor quando o preço do leite pago pela indústria não permite a obtenção de lucro ou mesmo quando não cobre os custos de produção. Além disso, o processamento do queijo é simples, não requer grandes investimentos em equipamentos e, quando realizado com qualidade, agrega valor ao produto (Aquino et al., 2009).

$\mathrm{O}$ atual enfoque de mercado dos produtos de origem animal tem sido direcionado à busca de alimentos com menores teores de gordura e atributos funcionais (Silva et al., 2007). A alimentação da vaca pode influenciar no valor nutritivo do leite e dos derivados lácteos, como o queijo, uma vez que alimentos saudáveis são cada vez mais procurados pelos consumidores (Fernandes et al., 2008).

O queijo minas frescal é um derivado do leite que contém em sua composição mais de $20 \%$ de gordura e uma das características do leite bovino é a grande quantidade de ácidos graxos saturados provenientes da síntese de novo que ocorre na glândula mamária. Consequentemente, a imagem nutricional da gordura do leite tem sofrido um impacto negativo nas últimas décadas, uma vez que esses ácidos graxos têm sido associados à elevação dos níveis de colesterol e ao risco de doenças cardíacas (Fernandes et al., 2008). Assim, manipular a gordura do leite visa atender à demanda do mercado consumidor, cada vez mais exigente em relação ao consumo de determinadas gorduras saturadas, em razão de seus efeitos nocivos à saúde humana (Eifert et al., 2006).

O volumoso corresponde a uma fração significativa da dieta de vacas leiteiras e, desta forma, pode influenciar as características físico-químicas do leite e de seus derivados (Grandison, 1986).

A cana-de-açúcar, as silagens de sorgo e girassol e a pastagem de capins tropicais são culturas tolerantes aos baixos índices pluviométricos e constituem alternativas à silagem de milho em regiões semiáridas. O sorgo é uma cultura de grande resistência, exige menos umidade para completar seu ciclo produtivo em relação à cultura do milho, tem maior capacidade de retirar a água do solo, devido o seu denso sistema radicular, e sua silagem é de boa qualidade, podendo se equiparar à do milho. As pastagens no verão garantem boa produção, porém essa produção não é suficiente para atender às exigências de animais em lactação, uma vez que no período de estiagem as pastagens se tornam pouco produtivas e de baixa qualidade. A cana-de-açúcar é uma forragem verde que tem maior valor nutritivo no período seco, sendo ótima opção para suplementação de vacas leiteiras, devido ao seu alto teor energético. O girassol é uma cultura anual e seu menor ciclo de produção, a capacidade em utilizar a água disponível no solo e a tolerância à ampla faixa de temperatura são fatores que têm estimulado seu cultivo para a produção de silagem. Indicase a semeadura do girassol para ensilagem após a colheita da cultura principal em período de safrinha ou em locais onde a deficiência hídrica torna inviáveis culturas tradicionalmente utilizadas para esse propósito, como milho e sorgo. Todavia, relatos da literatura (Dias et al., 2001; Queiroz et al., 2008; Elyas et al., 2009; Branco et al., 2011) comprovam que a utilização de diferentes volumosos na dieta de vacas em lactação pode implicar em variações do consumo, da digestibilidade de nutrientes e da produção e composição do leite.

Assim, objetivou-se com este trabalho avaliar a qualidade físico-química e sensorial e o perfil de ácidos graxos do queijo Minas frescal produzido com leite de vacas mestiças alimentadas com dietas contendo quatro volumosos (silagem de sorgo, silagem de girassol, cana-deaçúcar e pastagem de Panicum maximum cv. Tanzânia), assim como a composição físico-química do leite.

\section{Material e Métodos}

O experimento foi conduzido nos setores de Bovinocultura de Leite e Agroindustrial do Instituto Federal do Norte de Minas (IFNMG) - Campus Salinas. A composição e os parâmetros físico-químicos do leite e do queijo foram analisados no Laboratório de Bromatologia do IFNMG Campus Salinas, no Laboratório de Análise de Alimentos da UNIMONTES - Campus Janaúba e no Laboratório de Nutrição Animal da ESALQ-USP - Campus Piracicaba.

Foram utilizadas oito vacas mestiças $1 / 2$ sangue Holandês/Gir, com período de lactação de $180 \pm 12$ dias. Utilizaram-se quatro dietas experimentais, uma para cada um dos volumosos estudados (cana-de-açúcar, silagem de girassol, silagem de sorgo e pastagem de Panicum maximum cv. Tanzânia). As dietas foram formuladas para um mesmo nível de produção de leite e para ser isoproteicas, conforme descrito pelo NRC (2001) para atender potencial de produção de $20 \mathrm{~kg}$ de leite/dia com 4\% de gordura (Tabela 1). O experimento teve duração de 72 dias e foi dividido em quatro períodos de 18 dias: os 15 primeiros dias de cada período foram destinados à adaptação dos animais às dietas e os três últimos dias para coleta de dados, segundo metodologia descrita por Santos et al. (2006). O delineamento experimental adotado foi quadrado latino $4 \times 4$, com dois quadrados contemporâneos, cada um de quatro animais, quatro tratamentos e quatro períodos experimentais. 
Seis vacas foram mantidas em baias individuais de $20 \mathrm{~m}^{2}$ com parte do piso cimentado e parte de terra, separadas por cerca de arame liso com área coberta de $6 \mathrm{~m}^{2}$, dotadas de cochos e bebedouros. As duas vacas alimentadas com a dieta à base de pastagem de Panicum maximum cv. Tanzânia ficavam em piquetes individuais separados com cerca elétrica dotados de bebedouro e cocho com suplemento mineral. As vacas foram ordenhadas com ordenhadeira mecânica duas vezes ao dia, às $7 \mathrm{~h} 30$ e às $15 \mathrm{~h} 30$.

A pastagem de Panicum maximum cv. Tanzânia foi manejada para se obter altura de resíduo em torno de 40-45 cm, com massa de forragem pós-pastejo em torno de 2.500 a $3.000 \mathrm{~kg}$ de MS/ha. A disponibilidade de forragem foi obtida por meio da coleta de amostras de pastagem utilizando-se um quadrado com área conhecida. Com base nesses parâmetros, realizou-se o dimensionamento dos piquetes. Cada vaca ficou em piquetes separados e o período de pastejo foi de três dias. Quando necessário, foram utilizados animais reguladores conforme técnica de put and take, descrita por Mott \& Lucas (1952).

As dietas, para os animais em confinamento, foram fornecidas duas vezes por dia: às $8 \mathrm{~h}$ e às $16 \mathrm{~h}$. Os volumosos (cana-de-açúcar picada, silagem de sorgo e silagem de girassol) de cada tratamento foram pesados em balança digital, colocados nos respectivos cochos e misturados com parte do concentrado. A outra parte do concentrado foi fornecida na hora da ordenha. As sobras do cocho foram pesadas e registradas, e as dietas foram ajustadas de acordo com as sobras, mantendo-se a relação volumoso:concentrado com base na MS, de forma que as sobras representassem $10 \%$ da quantidade fornecida.

As vacas que estavam em sistema de pastejo receberam todo o concentrado no momento da ordenha (manhã e tarde). Para estimativa do consumo, utilizou-se a fibra em detergente ácido indigestível (FDAi) como indicador interno (Cochran et al., 1986), adotando-se como tempo de incubação in situ, 264 horas, de acordo com recomendação de Casali et al. (2008), sendo o consumo de MS (CMS) dado pela equação (Detmann et al., 2001): CMS (kg/dia) = $\{[(\mathrm{EF} \times \mathrm{CIF})-\mathrm{IS}] / \mathrm{CIFO}\}+\mathrm{CMSS}$, em que: $\mathrm{CIF}=$ concentração do indicador nas fezes; CIFO = concentração do indicador na forragem; CMSS = consumo de matéria seca de suplemento concentrado ( $\mathrm{kg} / \mathrm{dia}) ; \mathrm{EF}=$ excreção fecal (kg/dia); e IS = indicador presente no suplemento concentrado ( $\mathrm{kg} / \mathrm{dia})$.

A cada ciclo de pastejo, antes da entrada dos animais nos piquetes, foi realizada a coleta da forragem consumida para determinação da composição química. Para isso, utilizou-se a técnica do pastejo simulado (hand-plucked), coletando-se a forragem manualmente em pontos representativos do piquete (Johnson, 1978). Observaram-se o comportamento de pastejo dos animais e a altura do resíduo dos piquetes adjacentes recém-pastejados. Do material colhido em cada ponto do piquete, formou-se uma amostra composta para análises laboratoriais.

Após a agitação do leite no latão, amostras de leite de cada animal foram coletadas duas vezes ao dia nos últimos três dias de cada período, sendo feito um pool das amostras de leite da ordenha da manhã e da tarde, respeitando-se as

Tabela 1 - Proporção dos ingredientes e composição química das dietas, com base na matéria seca

\begin{tabular}{|c|c|c|c|c|}
\hline \multirow[b]{2}{*}{ Item } & \multicolumn{4}{|c|}{ Composição em ingredientes (\% MS) } \\
\hline & Cana-de-açúcar & Silagem sorgo & Silagem girassol & Capim-tanzânia \\
\hline Cana-de-açúcar & 49,60 & - & - & - \\
\hline Silagem de sorgo & - & 76,67 & - & - \\
\hline Silagem de girassol & - & - & 59,37 & - \\
\hline Capim-tanzânia & - & - & - & 75,77 \\
\hline Fubá de milho & 30,09 & 15,54 & 34,40 & 17,84 \\
\hline Farelo de soja & 17,41 & 5,62 & 4,60 & 4,40 \\
\hline Ureia/sulfato de amônio (9/1) & 1,00 & 0,90 & 0,99 & 0,83 \\
\hline Suplemento mineral & 1,90 & 1,27 & 0,64 & 1,16 \\
\hline Volumoso:concentrado (\%MS) & $50: 50$ & $77: 23$ & $60: 40$ & $76: 24$ \\
\hline \multicolumn{5}{|l|}{ Composição química } \\
\hline Proteína bruta (\%) & 14,68 & 14,48 & 14,77 & 13,74 \\
\hline Extrato etéreo (\%) & 5,60 & 5,31 & 7,54 & 5,97 \\
\hline Carboidratos totais (\%) & 66,06 & 65,53 & 61,35 & 67,47 \\
\hline Carboidratos não-fibrosos (\%) & 39,22 & 9,72 & 23,52 & 12,66 \\
\hline Fibra em detergente neutro (\%) & 35,08 & 62,53 & 43,27 & 60,65 \\
\hline $\mathrm{FDN}_{\mathrm{P}}(\%)$ & 32,02 & 56,24 & 38,16 & 54,81 \\
\hline Fibra em detergente ácido (\%) & 18,71 & 33,04 & 32,47 & 38,54 \\
\hline Lignina (\%) & 1,70 & 5,29 & 4,59 & 3,05 \\
\hline Nutrientes digestíveis totais $(\%)^{1}$ & 67,79 & 64,24 & 66,75 & 62,79 \\
\hline
\end{tabular}

FDNp = fibra em detergente neutro corrigida para proteína.

${ }^{1}$ Estimado pelo NRC (2001). 
mesmas proporções do volume de leite produzido diariamente. As amostras foram coletadas na proporção de $2 / 3$ pela manhã e $1 / 3$ pela tarde e posteriormente essas amostras foram encaminhadas refrigeradas ao laboratório de bromatologia e armazenadas à temperatura de $5{ }^{\circ} \mathrm{C}$ para análise no mesmo dia.

Para determinação das características físico-químicas do leite, foram realizadas as seguintes análises, em duplicada: acidez, com a utilização do alizarol, acidez titulável $\left({ }^{\circ} \mathrm{D}\right)$; pH, utilizando-se peagâmetro digital Tecnopon, densidade a $15^{\circ} \mathrm{C}$, pelo termolactodensímetro de Quevenne; percentual de gordura, pelo método de Gerber; proteína, pelo método Kjeldahl; cinzas, por incineração em mufla; e índice crioscópico $\left({ }^{\circ} \mathrm{H}\right)$, utilizando-se crioscópio eletrônico LAKTRON 312-L. O cálculo do extrato seco total (EST) foi obtido a partir do Disco de Ackermann; e o extrato seco desengordurado (ESD) pela subtração do teor de gordura (Brasil, 2006).

O queijo minas frescal foi processado de acordo com a técnica recomendada por Furtado \& Lourenço Neto (1994). No primeiro dia de coleta, o leite de cada dieta experimental, separadamente, foi pesado, filtrado e submetido à pasteurização lenta a $65{ }^{\circ} \mathrm{C}$ por 30 minutos. Após este tratamento térmico, o leite foi resfriado a $39^{\circ} \mathrm{C}$, temperatura em que foram adicionados $40 \mathrm{~mL} / 100 \mathrm{~L}$ da solução aquosa de cloreto de cálcio na concentração de $50 \%$ e 30 mL/100L de agente coagulante (coalho líquido $\mathrm{Ha} \mathrm{La}^{\circledR}$ ), Após 40 a 60 minutos, ocorreu a coagulação do leite. Em seguida, foi feito o corte da massa com uma faca inox em cubos de 1,5 a $2 \mathrm{~cm}$, intercalando a mexedura e o repouso para promover a dessoragem, que foi seguida da drenagem do soro e da salga da massa (700 g/100 L de sal branco refinado). Os queijos foram deixados nas formas por 1 hora com tempo de viragem de 30 minutos, sendo, então, embalados e pesados em balança digital para determinação do rendimento e conservados a $4{ }^{\circ} \mathrm{C}$. O rendimento bruto dos queijos foi calculado segundo a equação (Andreatta et al., 2009):

Rendimento bruto $(\mathrm{kg} / \mathrm{kg})$ = peso da formulação (leite mais os ingredientes) (kg) / massa de queijo após embalagem (kg).

O rendimento ajustado para o teor de umidade do queijo (Lucey \& Kelly, 1994) foi calculado considerando um valor de $57 \%$ como referência para a umidade do queijo minas frescal, conforme sugerido por Oliveira (1986).

Amostras do queijo minas frescal foram analisadas em duplicata quanto ao $\mathrm{pH}$, acidez $\left({ }^{\circ} \mathrm{D}\right)$, gordura, proteína, sólidos totais, cinzas, umidade (Brasil, 2006), textura e perfil de ácidos graxos. A textura das amostras de queijo foi determinada utilizando-se um texturômetro-modelo TAXT Express Marca Stable Micro Systems (Haslemere, Reino
Unido) (STABIC Micro Systems). Os dados foram coletados por meio do programa Texture Expert for Windows versão 1.20.

A extração dos ácidos graxos foi iniciada após o descongelamento das amostras, seguindo a metodologia descrita por Hara (1978), e a metilação de acordo com a descrição de Christie (1982). Uma alíquota de $1 \mu \mathrm{L}$ do extrato esterificado foi injetada no cromatógrafo e a identificação dos ácidos graxos foi feita pela comparação dos tempos de retenção. As porcentagens dos ácidos graxos foram obtidas utilizando-se o software-Chromquest 4.1 (Thermo Electron, Italy). Os ácidos graxos foram identificados por comparação dos tempos de retenção dos ésteres metílicos das amostras com padrões de ácidos graxos de manteiga e quantificados por normalização das áreas dos ésteres metílicos. Os resultados dos ácidos graxos foram expressos em mg/g de gordura.

A qualidade nutricional da fração lipídica foi avaliada pelos dados de composição em ácidos graxos, empregandose os seguintes índices:

1) índice de aterogenecidade $(\mathrm{IA})=\{(\mathrm{C} 12: 0+(4 \times \mathrm{C} 14: 0)$ + C16:0)\}/(“ácidos graxos monoinsaturados $+\sum \omega 6+\sum \omega 3$ ) (Ulbricth \& Southage, 1991); 2) índice de trombogenicidade $(\mathrm{IT})=(\mathrm{C} 14: 0+\mathrm{C} 16: 0+\mathrm{C} 18: 0) /\left\{\left(0,5 \times \sum\right.\right.$ Ácidos graxos monoinsaturados $)+\left(0,5 \times \sum \omega 6+\left(3 \times \sum \omega 3\right)+\left(\sum \omega 3 / \sum \omega 6\right)\right\}$ (Ulbricth \& Southage, 1991); 3) razão entre ácidos graxos hipercolesterolêmicos e hipocolesterolêmicos $=(\mathrm{C} 14: 0+$ C16:0) / (monoinsaturado + poliinsaturado) (Costa et al., 2008); 4) ácidos graxos desejáveis (AGD) = (insaturados + C18:0) (Costa et al., 2008); 5) razão entre ácidos graxos poliinsaturados e ácidos graxos saturados (Costa et al., 2008).

Para as análises microbiológicas dos queijos, as embalagens foram desinfetadas com álcool 70\%. Em várias regiões do queijo, foram retiradas porções, que foram pesadas em balança analítica (25 g de cada amostra) e colocadas em sacos plásticos estéreis com $225 \mathrm{~mL}$ de água peptonada $0,1 \%$ estéril para cada amostra (diluição $10^{-1}$ ) e homogeneizadas em Stomacher. A determinação do NMP (número mais provável) de coliformes a $35^{\circ} \mathrm{C}$ foi realizada a partir da diluição $10^{-1}$. Alíquotas de $1 \mathrm{~mL}$ foram transferidas para tubos de ensaio contendo tubos de Durhan invertidos, imersos em caldo lauril sulfato de sódio, sendo realizadas as diluições decimais subsequentes até $10^{-3}$. As amostras foram incubadas a $35^{\circ} \mathrm{C}$ por 48 horas. Para confirmação da presença de coliformes totais, foi feita a inoculação dos tubos positivos em caldo verde brilhante. A confirmação da presença de coliformes a $45{ }^{\circ} \mathrm{C}$ foi feita por meio da inoculação em caldo E. coli, a partir de tubos positivos na análise de coliformes totais, com incubação em temperatura seletiva de $45^{\circ} \mathrm{C}$ por 48 horas. O resultado foi expresso em 
NMP de coliformes a $35^{\circ} \mathrm{C}$ e coliformes a $45^{\circ} \mathrm{C}$ por grama, conforme Brasil (2003).

A avaliação dos queijos pelos julgadores não treinados foi realizada utilizando-se o teste de ordenação da preferência descrito por Meilgaard et al. (1999). A análise sensorial do queijo foi feita em quatro períodos, com 24 provadores por período, em cabines com luz branca, e as amostras foram codificadas e cortadas em cubos, com peso de $25 \mathrm{~g}$, e fornecidas em copinhos descartáveis. As amostras, com seus respectivos códigos, foram servidas simultaneamente e classificadas pelos provadores em ordem crescente de preferência para cada atributo avaliado (aparência, consistência, sabor e odor) dando-se a nota de valor 1 para a menos preferida e 4 para a mais preferida. Os dados foram avaliados calculando-se a diferença mínima significativa (DMS) da soma de ordens de cada amostra de acordo com o Método de Friedman (níveis de significância de 5\%) (Meilgaard et al., 1999).

Os dados relativos à composição físico-química do leite e do queijo foram submetidos à análise de variância e, quando significativa, as médias dos tratamentos foram comparadas pelo teste de Tukey a 5\% de probabilidade, utilizando-se o programa estatístico SAEG (versão 8.0).

\section{Resultados e Discussão}

Os teores de cinzas e extrato seco total foram iguais $(\mathrm{P}>0,05)$ para todas as dietas avaliadas. No entanto, o teor de gordura do leite foi maior para vacas alimentadas com dietas com silagem de sorgo e capim-tanzânia, enquanto a proteína e o extrato seco desengordurado foram maiores para a dieta com cana-de-açúcar (Tabela 2).

O maior teor de gordura encontrado no leite dos animais alimentados com dietas à base de silagem de sorgo e de pastagem de Panicum maximum cv. Tanzânia se deve, possivelmente, à maior relação volumoso:concentrado e, consequentemente, à maior proporção de fibra em detergente neutro nestas dietas (Tabela 1). De acordo com Van Soest (1994), a fibra proporciona maior produção de acetato no rúmen, que é um precursor de gordura a partir da síntese de novo na glândula mamária.

De outra forma, o menor teor de gordura observado no leite das vacas alimentadas com a dieta à base de silagem de girassol pode ser explicado pelo maior teor de extrato etéreo desta dieta (7,54\%), que pode ter limitado a síntese de novo deácidos graxos, pela própria inibição das enzimas envolvidas neste processo pelos ácidos graxos de cadeia longa de origem vegetal e/ou por meio de alguns intermediários trans dos ácidos graxos de cadeia longa advindos da biohidrogenação ruminal (Palmquist et al., 1993).

O conteúdo mais elevado de proteína (\%) no leite dos animais alimentados com a dieta com cana-de-açúcar se deve, possivelmente, ao maior consumo de carboidratos não-fibrosos (relação volumoso:concentrado 50:50), proporcionando maior aporte de carboidratos fermentáveis no rúmen. A maior disponibilidade de energia para microbiota ruminal pode implicar em aumento da proteína metabolizável, em função de uma possível elevação na síntese de proteína microbiana. Outra possível explicação poderia ser o aumento no aporte de proteína não degradada no rúmen, em função de maior taxa de passagem na dieta com menor relação volumoso:concentrado (50:50), associada à elevação na taxa de digestão ruminal. As relações volumoso:concentrado entre as dietas experimentais podem alterar os parâmetros da cinética de degradação ruminal (taxa de digestão e taxa de passagem) e, consequentemente, o fluxo de nutrientes para o intestino delgado, o que pode afetar a produção e composição do leite. Todavia, as dietas experimentais foram formuladas para um mesmo nível de produção e, apesar das diferentes relações volumoso:concentrado, não ocasionaram diferenças na produção de leite (média de 14 kg) nem na produção de leite corrigida para 4\% de gordura

Tabela 2 - Composição físico-química do leite de vacas mestiças alimentadas com dietas contendo diferentes volumosos

\begin{tabular}{|c|c|c|c|c|c|c|}
\hline Composição físico-química & \multicolumn{4}{|c|}{ Volumosos nas dietas } & CV (\%) & $\operatorname{Pr}>\mathrm{Fc}$ \\
\hline Gordura (\%) & $5,50 \mathrm{~b}$ & $6,23 a$ & $5,83 b$ & $6,1 \mathrm{a}$ & 8,37 & 0,0371 \\
\hline Cinza $(\%)$ & 0,70 & 0,74 & 0,72 & 0,73 & 10,89 & 0,7040 \\
\hline Extrato seco total (\%) & 14,68 & 14,93 & 14,38 & 14,59 & 4,45 & 0,4024 \\
\hline Extrato seco desengordurado (\%) & 9,19 a & $8,74 b$ & $8,59 b$ & $8,51 b$ & 3,78 & 0,0024 \\
\hline $\mathrm{pH}$ & 6,78 & 6,78 & 6,79 & 6,81 & 1,65 & 0,9240 \\
\hline Índice crioscópico $\left({ }^{\circ} \mathrm{H}\right)$ & $-0,5347$ & $-0,5288$ & $-0,5317$ & $-0,5293$ & $-0,88$ & 0,0707 \\
\hline
\end{tabular}

Médias com letras iguais na linha não diferem pelo teste Tukey a 5\% de significância. 
(média de $19 \mathrm{~kg}$ ), fato que pode ser explicado pelas diferenças no potencial de consumo das dietas com os diferentes volumosos. Neste trabalho não foi determinada a taxa de passagem para as dietas experimentais, assim, é possível apenas inferir quanto aos aspectos a ela relacionados.

Silva et al. (2004) avaliaram a produção e a composição do leite de vacas com média de $26 \mathrm{~kg} /$ dia alimentadas com diferentes proporções de silagem de girassol em substituição à silagem de milho e concluíram que a inclusão parcial da silagem de girassol mostrou-se viável, pois não afetou significativamente as produções de leite, de proteína ou de gordura, no entanto, a substituição total afetou negativamente as produções de leite, de proteína e de extrato seco total do leite, diferentemente deste trabalho, em que utilização da silagem de girassol como fonte exclusiva de volumoso em dietas para vacas em lactação não afetou a produção de leite e de extrato seco total do leite, o que pode ser explicado pela diferença nos níveis de produção das vacas, que, neste trabalho, foi de $14 \mathrm{~kg} / \mathrm{dia}$, enquanto no trabalho supracitado a média de produção de leite foi de $26 \mathrm{~kg} /$ dia.

Avaliando as silagens de milho e sorgo, Nascimento et al. (2008) verificaram os respectivos teores de gordura e proteína no leite, 4,42 e 3,09\%. Lima et al. (2009), também avaliando dietas com dois volumosos, capim-elefante e capim-tanzânia, observaram média de 3,4\% de gordura, de 3,18\% de proteína, 4,24\% de lactose e $12,01 \%$ de extrato seco total. Já Mendonça et al. (2004) não observaram em relação à composição do leite diferenças entre as dietas compostas com cana-de-açúcar e silagem de milho. Os teores de proteína, gordura e extrato seco total do leite neste estudo foram superiores (Tabela 2) aos demonstrados pelos autores supracitados, o que pode ser explicado pelas diferenças na composição genética das vacas e no nível de produção de leite, que foi maior para maioria dos trabalhos citados.
As dietas deste experimento foram formuladas para um potencial de produção de leite de $20 \mathrm{~kg}$ com $4 \%$ de gordura, e os teores de gordura verificados no leite variaram de 5,5 a 6,23\%, o que corresponde a uma produção média corrigida para $4 \%$ de gordura de $19 \mathrm{~kg}$ de leite/dia.

A densidade do leite foi maior para as vacas alimentadas com a cana-de-açúcar e silagem de sorgo em comparação àquelas dos tratamentos com silagem de girassol e pastagem de Panicum maximum cv. Tanzânia (Tabela 2). Os resultados de acidez, densidade, pH e índice crioscópio estão dentro dos requisitos mínimos de qualidade para o leite cru de uso industrial: acidez $\left(14\right.$ a $\left.18^{\circ} \mathrm{D}\right)$, gordura (mínimo 3,0\%), densidade a $15{ }^{\circ} \mathrm{C}(1,028$ a $1,034 \mathrm{~g} / \mathrm{mL})$, extrato seco desengordurado (mínimo 8,4\%) e índice crioscópio (máximo de $-0,530^{\circ} \mathrm{H}$ ) (Brasil, 2002).

As dietas não tiveram efeito sobre a concentração de cinzas, proteína, sólidos totais e umidade do queijo minas frescal. Quanto ao teor de gordura, as dietas com a canade-açúcar e a silagem de girassol foram iguais $(P>0,05)$ e superiores em relação à silagem de sorgo e à pastagem de Panicum maximum cv. Tanzânia, que não diferiram entre si $(\mathrm{P}>0,05)$. Apesar de o teor de gordura no leite ter sido menor para as dietas com silagem de girassol e cana-deaçúcar, no queijo o teor de gordura foi maior. No entanto, não houve diferença no rendimento do queijo minas frescal entre as dietas avaliadas (Tabela 3).

A composição físico-química do queijo está de acordo com a legislação vigente (Brasil, 2004) para o queijo minas frescal, que deve apresentar mais de $55 \%$ de umidade e teor de gordura no extrato seco de 25 a 44,9\% (Tabela 3). No entanto, apenas os queijos produzidos a partir da dieta com silagem de girassol e cana-de-açúcar, que foram similares $(\mathrm{P}>0,05)$ quanto ao teor de gordura, estavam dentro da classificação da legislação vigente, enquanto as outras dietas resultaram em queijos com os menores teores de gordura.

Tabela 3 - Composição físico-química, rendimento bruto e rendimento ajustado para o teor de umidade do queijo minas frescal produzido com leite de vacas mestiças alimentadas com diferentes volumosos

\begin{tabular}{|c|c|c|c|c|c|c|}
\hline \multirow[t]{2}{*}{ Composição físico-química } & \multicolumn{4}{|c|}{ Volumosos nas dietas } & \multirow[b]{2}{*}{ CV (\%) } & \multirow[b]{2}{*}{$\operatorname{Pr}>\mathrm{Fc}$} \\
\hline & Cana-de-açúcar & Silagem sorgo & Silagem girassol & Capim-tanzânia & & \\
\hline Gordura (\%) & $24,36 a$ & $21,39 b$ & $25,50 \mathrm{a}$ & $22,80 b$ & 22,15 & 0,4040 \\
\hline Proteína (\%) & 19,41 & 19,70 & 19,17 & 19,91 & 14,10 & 0,7375 \\
\hline Cinzas (\%) & 2,31 & 2,52 & 2,57 & 2,33 & 17,50 & 0,7596 \\
\hline Sólidos totais (\%) & 44,62 & 42,21 & 45,29 & 42,38 & 7,01 & 0,4088 \\
\hline Umidade (\%) & 55,38 & 57,79 & 54,71 & 57,62 & 5,42 & 0,4088 \\
\hline Rendimento bruto (kg/kg) & 4,42 & 4,08 & 4,64 & 4,45 & 17,68 & 0,7803 \\
\hline Rendimento ajustado (kg/kg) & 4,60 & 4,02 & 4,93 & 4,38 & 21,39 & 0,6012 \\
\hline Ácido láctico (\%) & 0,052 & 0,049 & 0,051 & 0,052 & 19,60 & 0,9722 \\
\hline $\mathrm{pH}$ & 6,72 & 6,68 & 6,64 & 6,58 & 1,31 & 0,2172 \\
\hline Textura (N) & 8,08 & 6,00 & 5,83 & 4,29 & 41,89 & 0,2614 \\
\hline
\end{tabular}

Médias com letras iguais na linha não diferem pelo teste Tukey a 5\% de significância. 
Rosa (2004) verificou em queijo minas frescal $62,5 \%$ de umidade e $20,5 \%$ de gordura quando avaliou os efeitos da atmosfera modificada e da irradiação sobre as características microbiológicas, físico-químicas e sensoriais do queijo. Observou ainda teores de cinzas em queijo minas frescal menores (1,94 e 1,91\%) que os encontrados neste trabalho.

A concentração de proteína no queijo varia até aproximadamente $40 \%$, dependendo da variedade de queijo, sendo que a proteína predominante é a caseína (Fox et al., 2000). Sangaletti et al. (2009), no estudo da vida útil do queijo minas frescal, encontrou teor de proteína de 21,52\% do primeiro ao décimo dia do processamento. Quanto maior o teor de caseínas, maior o rendimento do queijo (Ribeiro, 2001). Assim, pode-se dizer que as dietas avaliadas proporcionaram maior concentração de proteína no leite (Tabela 2), o que deve ter contribuído para o elevado rendimento dos queijos produzidos. Segundo Grandison (1986), os principais determinantes do rendimento de queijo são as concentrações de caseína e a gordura do leite. Souza \& Silva (2005) encontraram rendimento de $6,09 \mathrm{~kg} / \mathrm{kg}$ para o queijo Minas frescal tradicional processado com coalho bovino, cujos valores médios foram menores que os encontrados neste trabalho para todas as dietas avaliadas.

Os teores de sólidos totais do queijo são similares aos resultados encontrados por Caruso (1997), que descreveram média de 45,18\% de sólidos totais em queijos minas frescal. Esse autor relatou tendência de aumento do teor de sólidos totais devido à pequena dessoragem que ocorre com o aumento do tempo de armazenamento.

Não houve efeito das dietas sobre a acidez titulável, o $\mathrm{pH}$ e a textura do queijo (Tabela 3). Os teores de gordura, proteína, $\mathrm{pH}$ e acidez titulável foram semelhantes às médias encontradas por Sangaletti (2007), que descreveram valores médios de gordura de 21,25\%; proteína 21,62\%; pH, 6,24; e acidez titulável, 0,059, respectivamente. Os valores médios de pH $(6,66)$ e acidez titulável $(0,051)$ também foram semelhantes aos descritos por Marques \& Oliveira (2004), pH $(6,76)$ e acidez titulável (0,052\%) em queijo Minas frescal armazenado por um período de 30 dias. Rosa (2004) apresentou resultados parecidos para $\mathrm{pH}(6,71)$ e inferiores (0,28\%) de acidez em ácido láctico.

$\mathrm{Na}$ avaliação do perfil de ácidos graxos, foi encontrada menor $(\mathrm{P}<0,00)$ proporção de ácidos graxos saturados (AGS) no queijo produzido a partir do leite de vacas alimentadas com a dieta à base de silagem de girassol em relação às demais (cana-de-açúcar, silagem de sorgo e pastagem de Panicum maximum cv. Tanzânia). Apenas para as concentrações de C4:0 e o C22:0 não houve diferença entre as dietas avaliadas. A proporção de ácidos graxos monoinsaturados foi maior no queijo produzido a partir da dieta com silagem de girassol, com exceção do C17:1, C18:1(C11), C18:1(C13) e o C20:1, que foram semelhantes entre todas as dietas avaliadas. A concentração de ácidos graxos poliinsaturados foi maior no queijo produzido a partir da dieta com silagem de girassol em relação aos das dietas à base de cana, silagem de sorgo e pastagem de Panicum maximum cv. Tanzânia (Tabela 4).

O queijo produzido a partir da dieta com silagem de girassol apresentou melhor perfil nutricional de ácidos graxos em relação às outras dietas (Tabela 4). Dessa forma, o queijo produzido com dieta à base de silagem de girassol apresentou menor concentração de ácidos graxos saturados (30\% menor) e maior concentração de ácidos graxos monoinsaturados (42,3\% maior) e poliinsaturados (54,8\% maior), principalmente o C18:1 (oleico) e C18:2 Cis 9 trans 11 (ácido linoleico conjugado).

Essa maior proporção de ácidos graxos polinsaturados no queijo produzido com dieta à base de silagem de girassol é semelhante aos resultados verificados por Valdez et al. (1988) quando compararam a silagem de milho, silagem de milho com girassol e silagem de girassol na produção e na composição do leite de vacas. Esses autores observaram no leite de vacas alimentadas com silagem de milho maior proporção de ácidos graxos de cadeia média e saturados (AGS), C14:0, C16:0, e menor proporção de ácidos graxos de cadeia longa e poliinsaturados (AGP) C18:1 e C18:2. Valdez et al. (1988) compararam a silagem de milho com a mistura silagem de milho com girassol e não observaram diferença significativa no teor de ácidos graxos saturados, C14:0 e/ou C18:0, ou C20:0, mas a mistura milho com girassol apresentou maior proporção de AGP, C18:1 e C18:2. Segundo estes autores, o aumento significativo de ácidos graxos poliinsaturados do leite de vacas alimentadas com a mistura de silagem de milho com girassol pode indicar que maior quantidade de ácido linoleico (18:2), que predomina no óleo da semente de girassol, não sofre hidrogenação ruminal e é absorvida pelo intestino delgado. Ainda segundo esses autores, a menor proporção de ácidos graxos saturados no leite produzido com a silagem de girassol pode indicar inibição parcial da síntese de novo na glândula mamária pelo óleo do girassol, que é rico em ácidos graxos poliinsaturados.

Resultados semelhantes aos encontrados neste estudo foram observados por Eifert et al. (2006), que avaliaram os efeitos do óleo de soja na dieta de vacas lactantes sobre o perfil de ácidos graxos (AG) do leite na $5 \underline{a}$ a $15^{\underline{a}}$ semanas da lactação e verificaram que, nas dietas que continham o óleo de soja em 3,9\% da dieta, houve aumento das concentrações de cis-9 C18:1 e dos isômeros cis-C18:1 totais em relação às dietas controle que não continham óleo. O óleo de soja reduziu em $43,7 \%$ os ácidos graxos 
de cadeia curta (AGCC) e em 49,1\% os ácidos graxos de cadeia média (AGCM), consequentemente, aumentando em 55,3\% os ácidos graxos de cadeia longa. A redução da proporção dos ácidos graxos de cadeias curtas e médias pode ser decorrente da diminuição de precursores da síntese de novo, acetato e $\beta$-hidroxibutirato, resultantes da fermentação ruminal, ou da inibição direta do complexo enzimático envolvido na síntese de novo pela ação dos ácidos graxos de cadeia longa dos óleos vegetais (Palmquist et al., 1993).

Neste trabalho, a concentração de ácido linoleico conjugado cis-9 trans-11 C18:2 (CLA) e ácidos graxos trans-C18:1 foi maior no queijo produzido com leite de vacas alimentadas com a silagem de girassol em relação aos demais volumosos (cana, silagem de sorgo e capimtanzânia) (Tabela 4). Quanto ao aumento de gorduras trans observado neste trabalho com a silagem de girassol, resultado similar foi descrito por Eifert et al. (2006) para dietas com óleo de soja (3,9\% na dieta). A concentração de trans-C18:1 é aumentada em situações com altas quantidades de lipídios insaturados na dieta (Bateman \& Jenkins, 1998), pois a população microbiana é muito sensível aos ácidos graxos insaturados (Bessa et al., 2000). A maior produção ruminal de isômeros trans-C18:1 em dietas com elevadas concentrações de lipídeos insaturados é um mecanismo de defesa da microbiota, o que permite às bactérias manter a integridade da membrana celular, uma vez que ácidos graxos trans são menos tóxicos que os de configuração cis. De acordo com Parodi (1999), elevar a concentração de ácidos graxos insaturados tem de grande importância, uma vez que estes são precursores da síntese endógena de CLA cis-9 trans-11 C18:2, que tem propriedades anticancerígenas, além de outras, benéficas à saúde humana, como a redução de risco de doenças coronarianas e aterosclerose e diminuição da incidência de tumores mamários.

Tabela 4 - Concentração de ácidos graxos do queijo minas frescal produzido do leite de vacas mestiças alimentadas com dietas contendo diferentes volumosos

\begin{tabular}{|c|c|c|c|c|c|c|}
\hline \multirow[t]{2}{*}{ Componentes } & \multicolumn{4}{|c|}{ Volumosos nas dietas } & \multirow[b]{2}{*}{ CV (\%) } & \multirow[b]{2}{*}{$\operatorname{Pr}>\mathrm{Fc}$} \\
\hline & Cana-de-açúcar & Silagem sorgo & Silagem girassol & Capim-tanzânia & & \\
\hline \multicolumn{7}{|c|}{ mg/g de gordura } \\
\hline Saturados & $78,61 \mathrm{a}$ & $75,05 a$ & $51,77 b$ & $72,66 a$ & 5,35 & 0,0000 \\
\hline $\mathrm{C}_{4}: 0$ & 2,83 & 2,57 & 2,32 & 3,26 & 28,29 & 0,3964 \\
\hline$C_{6}: 0$ & $2,17 \mathrm{a}$ & $1,94 \mathrm{a}$ & $1,16 \mathrm{~b}$ & $2,11 \mathrm{a}$ & 25,36 & 0,0354 \\
\hline $\mathrm{C}_{8}: 0$ & $1,44 \mathrm{a}$ & $1,25 \mathrm{a}$ & $0,57 b$ & $1,25 a$ & 26,20 & 0,0065 \\
\hline $\mathrm{C}_{10}: 0$ & $3,35 a$ & $2,88 \mathrm{a}$ & $1,06 b$ & $2,64 \mathrm{a}$ & 27,57 & 0,0027 \\
\hline $\mathrm{C}_{12}: 0$ & $4,34 a$ & $3.70 \mathrm{a}$ & $1,32 b$ & $3,23 a$ & 27,31 & 0,0019 \\
\hline $\mathrm{C}_{14}: 0$ & $0,36 \mathrm{a}$ & $0,28 b$ & $0,09 \mathrm{c}$ & $0,22 b$ & 21,13 & 0,0001 \\
\hline $\mathrm{C}_{15}: 0$ & $2,16 \mathrm{a}$ & $1,77 \mathrm{~b}$ & $0,95 c$ & $2,01 \mathrm{a}$ & 7,65 & 0,0000 \\
\hline $\mathrm{C}_{16}: 0$ & $36,26 a$ & $35,20 a$ & $19,05 b$ & $26,37 b$ & 16,58 & 0,0009 \\
\hline $\mathrm{C}_{17}: 0$ & $1,02 \mathrm{a}$ & $0,82 b$ & $0,71 b$ & $1,16 \mathrm{a}$ & 16,34 & 0,0052 \\
\hline $\mathrm{C}_{18}: 0$ & $7,61 b$ & $7,62 b$ & $12,90 \mathrm{a}$ & $11,80 \mathrm{a}$ & 16,61 & 0,0009 \\
\hline $\mathrm{C}_{22}: 0$ & 0,08 & 0,06 & 0,03 & 0,05 & 35,40 & 0,0588 \\
\hline Monoinsaturados & $27,15 b$ & $25,29 b$ & $46,49 a$ & $28,96 b$ & 14,14 & 0,0001 \\
\hline $\mathrm{C}_{14}: 1$ & $1,98 \mathrm{a}$ & $1,79 \mathrm{a}$ & $0,73 c$ & $1,32 b$ & 18,81 & 0,0001 \\
\hline $\mathrm{C}_{16}: 1$ & $2,49 a$ & $2,07 \mathrm{a}$ & $1,12 b$ & $1,81 \mathrm{a}$ & 18,20 & 0,0008 \\
\hline $\mathrm{C}_{17}^{10}: 1$ & 0,24 & 0,25 & 0,12 & 0,15 & 59,96 & 0,3026 \\
\hline $\mathrm{C}_{18}: 1(\mathrm{~T} 6-\mathrm{T} 9)$ & $0,26 b$ & $0,29 b$ & $1,39 a$ & $0,38 b$ & 104,74 & 0,0414 \\
\hline $\mathrm{C}_{18}: 1(\mathrm{~T} 10-\mathrm{T} 12)$ & $1,12 \mathrm{c}$ & $1,35 c$ & $14,69 a$ & $2,95 b$ & 20,42 & 0,0000 \\
\hline $\mathrm{C}_{18}: 1(\mathrm{~T} 16)$ & $0,13 c$ & $0,19 \mathrm{c}$ & $0,58 a$ & $0,28 b$ & 19,22 & 0,0000 \\
\hline $\mathrm{C}_{18}^{10}: 1 \mathrm{C}_{9}$ & $20,32 b$ & $18,73 \mathrm{~b}$ & $26,97 \mathrm{a}$ & $21,43 b$ & 15,89 & 0,0290 \\
\hline $\mathrm{C}_{18}: 1 \mathrm{C}_{11}$ & 0,45 & 0,36 & 0,45 & 0,41 & 15,11 & 0,2241 \\
\hline $\mathrm{C}_{18}: 1 \mathrm{C}_{12}$ & $0,10 \mathrm{~b}$ & $0,11 b$ & $0,31 \mathrm{a}$ & $0,09 b$ & 32,46 & 0,0001 \\
\hline $\mathrm{C}_{18}: 1 \mathrm{C}_{13}$ & 0,05 & 0,04 & 0,03 & 0,04 & 39,20 & 0,2842 \\
\hline $\mathrm{C}_{20}: 1$ & 0,12 & 0,11 & 0,11 & 0,13 & 32,17 & 0,8144 \\
\hline Poliinsaturados & $2,84 \mathrm{~b}$ & $2,32 b$ & $5,73 a$ & $2,71 b$ & 18,80 & 0,0000 \\
\hline $\mathrm{C}_{18}: 2 \mathrm{~T}_{11} \mathrm{C}_{15}$ (CLA) & 0,02 & 0,02 & 0,10 & 0,09 & 101,84 & 0,1597 \\
\hline $\mathrm{C}_{18}: 2 \mathrm{C}_{9} \mathrm{~T}_{11}$ (CLA) & $0,48 b$ & $0,52 b$ & $3,82 \mathrm{a}$ & $0,96 b$ & 35,41 & 0,0000 \\
\hline $\mathrm{C}_{18}: 2 \mathrm{C}_{9} \mathrm{C}_{12}$ (CLA) & 1,85 & 1,37 & 1,55 & 1,06 & 23,30 & 0,0503 \\
\hline $\mathrm{C}_{18}^{18}: 3 \mathrm{w} 6$ & 0,04 & 0,02 & 0,01 & 0,01 & 148,95 & 0,4129 \\
\hline $\mathrm{C}_{18}: 3 \mathrm{w} 3$ & $0,20 \mathrm{~b}$ & $0,16 b$ & $0,08 b$ & $0,37 \mathrm{a}$ & 46,38 & 0,0059 \\
\hline $\mathrm{C}_{20}: 4$ & 0,17 & 0,14 & 0,11 & 0,11 & 44,44 & 0,4544 \\
\hline $\mathrm{C}_{20}: 5$ & 0,08 & 0,10 & 0,05 & 0,11 & 94,29 & 0,7435 \\
\hline
\end{tabular}

Médias seguidas de letras iguais nas linhas não diferem pelo teste Tukey a 5\% de significância. 
Oliveira et al. (2009) avaliaram a composição química e o perfil de ácidos na gordura do leite e do queijo mussarela de búfalas alimentadas com fontes de lipídeos à base de óleo de soja e concluíram que as fontes lipídicas reduziram as concentrações de ácidos graxos saturados e aumentaram as de ácidos graxos insaturados. Os ácidos graxos encontrados na mussarela, em ordem decrescente, foram: palmítico, oleico, láurico e esteárico. O óleo de soja apresentou maior capacidade de elevar as concentrações do ácido linoleico conjugado (CLA) e do ácido vaccênico no leite e no queijo mussarela. Neste trabalho, a ordem decrescente de ácidos graxos foram: o palmítico, o oleico, o trans-C18:1(T10-T12), o esteárico e o CLA.

O teor mais elevado de extrato etéreo na dieta com silagem de girassol (7,54\%) em relação às demais (média de $5,63 \%)$, associado à maior proporção de ácidos graxos insaturados, implicou em menor teor de gordura no leite produzido e em melhor perfil de ácidos graxos no queijo.

Os índices de aterogenicidade, trombogenecidade e a relação hiper/hipocolesterol relacionam os ácidos pró e antiaterogênicos. No queijo produzido com o leite de vacas alimentadas com silagem de girassol, esses índices foram menores $(\mathrm{P}<0,05)$ em relação aos outros queijos produzidos a partir do leite produzido pelos demais volumosos (cana, silagem de sorgo e capim-tanzânia) (Tabela 5). Quanto aos ácidos graxos desejáveis, o queijo produzido com dieta a base de silagem de girassol foi superior aos demais tratamentos, assim como, a relação ácidos graxos poliinsaturados/ácidos graxos saturados (AGP/AGS), com diferença significativa $(P<0,05)$ em relação aos demais.
A análise microbiológica do queijo foi realizada com o objetivo de verificar se o produto atendia aos requisitos microbiológicos previstos pelo MAPA (Brasil, 2004) para a realização da análise sensorial. Foi observada uma possível contaminação após a pasteurização, ou seja, no processamento, no entanto, a população de coliformes a $45^{\circ} \mathrm{C}$ encontrou-se dentro do limite tolerado $\left(5 \times 10^{3} \mathrm{NMP} / \mathrm{g}\right)$ para queijo de alta umidade com coagulação enzimática, prevista pela legislação (Brasil, 2004), o que permitiu a realização da análise sensorial.

Para o atributo aparência, o queijo produzido com leite de vacas alimentadas com dieta à base de silagem de girassol teve maior preferência entre os provadores em relação aos demais queijos (Tabela 6).

Quanto à consistência, os queijos produzidos a partir das dietas com silagem de girassol e cana-de-açúcar foram mais preferidos pelos provadores em relação aos queijos produzidos a partir das dietas com silagem de sorgo e pastagem de Panicum maximum cv. Tanzânia (Tabela 6). Quanto ao atributo sabor, o queijo produzido a partir da dieta com silagem de girassol foi superior $(\mathrm{P}<0,05)$ ao produzido com pastagem de Panicum maximum cv. Tanzânia, enquanto os queijos produzidos a partir das dietas com silagem de sorgo e cana-de-açúcar foram intermediários e iguais $(\mathrm{P}>0,05)$ entre si. Quanto ao odor, os queijos dos grupos alimentados com silagem de girassol, cana-de-açúcar e silagem de sorgo e pastagem de Panicum maximum cv. Tanzânia não diferiram $(\mathrm{P}>0,05)$ entre si.

Os resultados da análise sensorial indicaram maior preferência pelo queijo produzido a partir da dieta com

Tabela 5 - Índices de qualidade nutricional em queijo minas frescal produzido do leite de vacas mestiças alimentadas com dietas contendo diferentes volumosos

\begin{tabular}{|c|c|c|c|c|c|c|}
\hline \multirow[t]{2}{*}{ Variáveis } & \multicolumn{4}{|c|}{ Volumosos nas dietas } & \multirow[b]{2}{*}{ CV (\%) } & \multirow[b]{2}{*}{$\mathrm{Pr}>\mathrm{FC}$} \\
\hline & Cana-de-açúcar & Silagem sorgo & Silagem girassol & Capim-tanzânia & & \\
\hline Aterogenecidade & $3,63 a$ & $3,69 a$ & $1,06 b$ & $3,10 \mathrm{a}$ & 17,34 & 0,0000 \\
\hline Trombogenecidade & $3,84 a$ & $4,28 a$ & $1,65 b$ & $3,36 a$ & 23,30 & 0,0020 \\
\hline Hiper/Hipocolesterolêmicos & $1,54 a$ & $1,73 a$ & $0,49 b$ & $1,23 a$ & 28,77 & 0,0019 \\
\hline AG desejáveis & $37,69 b$ & $35,15 b$ & $65,10 a$ & $43,48 b$ & 13,24 & 0,0000 \\
\hline AGP/AGS & $0,04 \mathrm{~b}$ & $0,03 \mathrm{~b}$ & $0,11 \mathrm{a}$ & $0,04 \mathrm{~b}$ & 24.75 & 0,0000 \\
\hline
\end{tabular}

Médias seguidas de letras distintas nas linhas diferem pelo teste Tukey a 5\% de significância.

Tabela 6 - Soma dos pontos do teste de ordenação para atributos sensoriais em queijo minas frescal produzido do leite de vacas alimentadas com dietas contendo diferentes volumosos

\begin{tabular}{lcccc}
\hline Atributos & Cana-de-açúcar & Silagem sorgo & Silagem girassol & Capim-tanzânia \\
\hline Aparência & $248 \mathrm{~b}$ & $204 \mathrm{~b}$ & $301 \mathrm{a}$ & $207 \mathrm{~b}$ \\
Consistência & $274 \mathrm{a}$ & $208 \mathrm{~b}$ & $276 \mathrm{a}$ & $209 \mathrm{~b}$ \\
Sabor & $239 \mathrm{ab}$ & $238 \mathrm{ab}$ & $277 \mathrm{a}$ & $206 \mathrm{~b}$ \\
Odor & $243 \mathrm{a}$ & $233 \mathrm{a}$ & $258 \mathrm{a}$ & $226 \mathrm{a}$ \\
$\mathrm{N}$ & 96 & 96 & 96 & 96 \\
\hline
\end{tabular}

Totais com mesma letra na linha não diferem entre si $(\mathrm{P}>0,05)$ pelo teste de Friedman apud Ferreira et al. $(2000)$. N = número de provadores 
silagem de girassol em relação às outras dietas avaliadas. O queijo produzido a partir do leite de vacas alimentadas com dieta à base de pastagem de Panicum maximum cv. Tanzânia foi o menos aceito de acordo com resultados da análise sensorial. Os queijos produzidos a partir da dieta com cana-de-açúcar e silagem de sorgo tiveram aceitação intermediária. Sangaletti et al. (2009) não verificaram diferença nos atributos aparência, cor, odor, sabor e textura do queijo minas frescal obtido direto do laticínio e analisados com 1, 10, 20 e 30 dias de vida útil após o processamento. Andreatta (2006) também encontrou resultados parecidos aos de Sangaletti (2007) quando avaliou a aceitação do consumidor do queijo minas frescal no período de armazenamento de 30 dias e concluiu que, apesar das alterações químicas e microbiológicas ocorridas durante o período de armazenamento, essas variações não foram suficientes para provocar alterações sensoriais detectáveis pelos provadores. No entanto, esses autores não avaliaram a dieta fornecida às vacas para produção do leite utilizado no processamento, mas apenas o tempo de armazenamento do queijo minas frescal. Não foram encontrados na literatura trabalhos com avaliação das características sensoriais do queijo minas frescal produzido com o leite de vacas alimentadas com dietas com diferentes volumosos.

\section{Conclusões}

O tipo de volumoso da dieta de vacas mestiças (canade-açúcar, silagem de sorgo, silagem de girassol e pastagem de Panicum maximum cv. Tanzânia) não afeta o rendimento do queijo minas frescal produzido com o leite desses animais. Entretanto, o teor de gordura é maior no queijo produzido a partir do leite de vacas mestiças alimentadas com dietas à base de silagem de girassol e cana-de-açúcar. A dieta com silagem de girassol possibilita a produção de queijo com melhor qualidade nutricional, por apresentar melhor perfil de ácidos graxos, e com maior preferência pelos julgadores no teste de análise sensorial.

\section{Agradecimentos}

Ao Banco do Nordeste / Fundeci, pelo auxílio financeiro à pesquisa; à FAPEMIG e ao CNPq, pelo auxílio com bolsas; e ao IFNMG - Campus Salinas.

\section{Referências}

ANDREATTA, E.; FERNANDES, A.M.; SANTOS, M.V. et al. Quality of Minas frescal cheese prepared from milk with different somatic cell counts. Pesquisa Agropecuária Brasileira, v.44, p.320-326, 2009.
AQUINO, A.A.; PEIXOTO JÚNIOR, K.C.; GIGANTE, M.L. et al. Efeito de níveis crescentes de uréia na dieta de vacas leiteiras sobre a composição e rendimento de fabricação de queijos minas frescal. Brazilian Journal Veterinary Research Animal Science, v.46, n.4, p.273-279, 2009.

BATEMAN, H.G.; JENKINS, T.C. Influence of soybean oil in high fiber diets fed to nonlactating cows on ruminal unsaturated fatty acids and nutrient digestibility. Journal of Dairy Science, v.81, p.2451-2458, 1998.

BRANCO, R.H.; RODRIGUES, M.T.; SILVA, M.M.C. et al. Desempenho de cabras em lactação alimentadas com dietas com diferentes níveis de fibra oriundas de forragem com maturidade avançada. Revista Brasileira de Zootecnia, v.40, n.5, p.1061-1071, 2011.

BRASIL. Instrução Normativa $\mathrm{n}^{0}$ 51, de 20 de setembro de 2002. Aprova os regulamentos técnicos de produção, identidade e qualidade do leite. Diário Oficial da União, Brasília, DF, set. 2002. Seção 1, p.13-21.

BRASIL. Ministério da Agricultura, Pecuária e Abastecimento. Métodos Oficiais para Análises Microbiológicas para Controle de Produtos de Origem Animal e Água. Instrução Normativa $\mathrm{n}$ o 62 de agosto de 2003.

BRASIL. Ministério da Agricultura, Pecuária e Abastecimento. Métodos analíticos oficiais físico-químicos para controle de leite e produtos lácteos. Instrução Normativa $\mathrm{n}^{\circ} .22$ de 14 de dezembro de 2006. Diário Oficial da União, Brasília, DF, 2006. Disponível em: <http://www.agricultura.gov.br>. Acesso em: 17 out. 2008

BRASIL. Ministério da Agricultura, Pecuária e Abastecimento. Secretaria de Defesa Agropecuária. Departamento de Inspeção de Produtos de Origem Animal. Instrução Normativa $n^{0} 4$, de 01 de março de 2004. Diário Oficial da União, Brasília, DF, 2004. Disponível em: <http://www.agricultura.gov.br>. Acesso em: 17 out. 2008.

CHRISTIE, W.W. A simple procedure for rapid transmethilation of glycerolipids and cholesterol esters. Journal of Lipid Research v.23, p.1072, 1982.

COSTA, R.G.; FERNANDES, M.F.; QUEIROGA, R.C.R.E. et al Características químicas e sensoriais do leite de cabras Moxotó alimentadas com silagem de maniçoba. Revista Brasileira de Zootecnia, v.37, n.4, p.694-702, 2008.

CASALI, A.O.; DETMANN, E.; VALADARES FILHO, S.C. et al. Influência do tempo de incubação e do tamanho de partículas sobre os teores de compostos indigestíveis em alimentos e fezes bovinas obtidos por procedimentos in situ. Revista Brasileira de Zootecnia, v.37, n.2, p.335-342, 2008

COCHRAN, R.C.; ADAMS, D.C.; WALLACE, J.D. Predicting digestibility of different diets whith internal markers: evaluation of four potential markers. Journal of Animal Science, v.63, n.5, p.1476-1483, 1986.

DETMANN, E.; PAULINO, M.F.; ZERVOUDAKIS, J.T. et al. Cromo e indicadores internos na determinação do consumo de novilhos mestiços, suplementados, a pasto. Revista Brasileira de Zootecnia, v.30, n.5, p.1600-1609, 2001.

DIAS, A.M.A.; BATISTA, A.M.V.; FERREIRA, M.A. et al. Efeito do estádio vegetativo do sorgo (Sorghum bicolor,(L) Moench) sobre a composição química da silagem, consumo, produção e teor de gordura do leite para vacas em lactação, em comparação à silagem de milho (Zea mays (L.). Revista Brasileira de Zootecnia, v.30, n.6, p.2086-2092, 2001 (supl.).

ELYAS, A.C.W.; PAIVA, P.C.A; LOPES, F.C.F. et al. Avaliação do modelo CNCPS na predição do consumo de matéria seca em vacas da raça Holandesa em pastejo. Revista Brasileira de Zootecnia, v.38, n.6, p.1096-1103, 2009.

EIFERT, E.C.; LANA, R.P.; LANNA, D.P.D. et al. Perfil de ácidos graxos do leite de vacas alimentadas com óleo de soja e monensina no início da lactação. Revista Brasileira de Zootecnia, v.35, n.1, p.219-228, 2006.

FERREIRA, V.L.P.; ALMEIDA, T.C.A.; PETTINELLI, M.L.C.V. et al. Análise sensorial: teste discriminativos e afetivos. Campinas: SBTA, 2000. 127p. 
FERNANDES, M.F.; QUEIROGA, R.C.R.E.; MEDEIROS, A.N. et al. Características físico-químicas e perfil lipídico do leite de cabras mestiças Moxotó alimentadas com dietas suplementadas com óleo de semente de algodão ou de girassol. Revista Brasileira de Zootecnia, v.37, n.4, p.703-710, 2008.

FOX, P.F.; GUINEE, T.P.; COGAN, T.M. et al. Fundamentals of cheese science. Gaithersburg: AN Aspen Publication, 2000. 587p.

FURTADO, M.M.; LOURENÇO NETO, J.P.M. Tecnologia de queijos: manual técnico para produção industrial de queijos. 1.ed. São Paulo: Dipemar, 1994. 118p.

GRANDISON, A. Causes of variation in milk composition and their effects on coagulation and cheesemaking. Dairy Industries International, v.51, n.3, p.21-24, 1986.

HARA, A.; RADIN, N.S. Lipid extraciton of tissues with lowtoxicity solvent. Analitical Biochemistry, v.90, p.420-426, 1978.

JOHNSON, A.D. Sample preparation and chemical analysis of vegetation. In: t'MANNETJE, L. (Ed.). Measurement of grassland vegetation and animal production. Aberystwyth: Commonwealth Agricultural Bureaux, 1978. p.96-102.

LIMA, M.L.P.; LEME, P.R.; PINHEIRO, M.G. et al. Vacas leiteiras mantidas em rotacionado de capim-elefante Guaçu e capim-tanzânia: produção e composição do leite. Disponível em: <http://www.infobibos.com/Artigos/2007>. Acesso em: 12 mar. 2009.

LUCEY, J.; KELLY, J. Cheese yield. Journal of the Society of Dairy Technology, v.47, n.1, p.1-14, 1994.

MARQUES, M.C.; OLIVEIRA, C.A.F. Avaliação das características físico-químicas do queijo Minas frescal produzido com leite contendo diferentes níveis de células somáticas. Pirassununga: FZEA/USP, 2004. 15p.

MEILGAARD, M.; CIVILLE, G.V.; CARR, B.T. Sensory evaluation techniques. Boca Raton: CRC Press, 1999. 2 v. 387p.

MENDONÇA, S.S.; CAMPOS, J.M.S.; VALADARES FILHO, S.C. et al. Consumo, digestibilidade aparente, produção e composição do leite e variáveis ruminais em vacas leiteiras alimentadas com dietas à base de cana-de-açúcar. Revista Brasileira de Zootecnia, v.33, n.2, p.481-492, 2004.

MOTT, G.O.; LUCAS, H.L. The design, conduct and interptretation of grazing trials on cultivated and improved pastures. In: INTERNATIONAL GRASSLAND CONGRESS, 6., 1952, Pensylvania. Proceedings... Pensylvania: State College Press. 1952. p.1380-1385.

NASCIMENTO, W.G.; PRADO, I.N.; JOBIM, C.C. et al. Valor nutritivo das silagens de milho e de sorgo e sua influência no desempenho de vacas leiteiras. Revista Brasileira de Zootecnia, v.37, n.5, p.896-904, 2008.

NATIONAL RESEARCH COUNSIL. Nutrient requirements of dairy cattle. 7.ed. Washington, 2001. 381p.

OLIVEIRA, J.S. Queijo: fundamentos tecnológicos. 2.ed. Campinas: Unicamp, 1986. 146p.
OLIVEIRA, R.L.; LADEIRA, M.M.; BARBOSA, M.A.A.F. et al. Composição química e perfil de ácidos graxos do leite e mussarela de búfalas alimentadas com diferentes fontes de lipídeos. Arquivo Brasileiro de Medicina Veterinária e Zootecnia, v.61, n.3, p.736-744, 2009.

PALMQUIST, D.L.; BEAULIEU, A.D.; BARBANO, D.M. Feed and animal factors influencing milk fat composition. Journal of Dairy Science, v.76, p.1753-1771, 1993.

PARODI, P.W. Conjugated linoleic acid and other anticarcinogenic agents of bovine milk fat. Journal of Dairy Science, v.82, p.1339-1349, 1999.

QUEIROZ, O.C.M.; NUSSIO, L.G.; SCHMIDT, P. et al. Silagem de cana-de-açúcar comparada a fontes tradicionais de volumosos suplementares no desempenho de vacas de alta produção. Revista Brasileira de Zootecnia, v.37, n.2, p.358-365, 2008.

RIBEIRO, E.P. Queijos. In: AQUARONE, E. et al. Biotecnologia industrial na produção de alimentos. São Paulo: Edgard Blücher, 2001. v.4. cap.8, p.225-253.

ROSA, V.P. Efeitos da atmosfera modificada e da irradiação sobre as características microbiológicas, físico-químicas e sensoriais do queijo Minas frescal. 2004. 155f. Dissertação (Mestrado em Ciência e Tecnologia de Alimentos) - Escola Superior de Agricultura Luiz de Queiroz, Universidade de São Paulo, Piracicaba.

SANGALETTI, N.; PORTO, E.; BRAZACA, S.G.C. et al. Estudo da vida útil de queijo Minas. Ciência e Tecnologia de Alimentos, v.29, n.2, p.262-269, 2009.

SANTOS, F.A.P.; CARMO, C.A.; MARTINEZ, J.C. et al. Desempenho de vacas em lactação recebendo dietas com diferentes teores de amido total, acrescidas ou não de levedura (Saccharomyces cerevisiae). Revista Brasileira de Zootecnia, v.35, n.4, p.1568-1575, 2006.

SILVA, B.O.; LEITE, L.A.; FERREIRA, M.I.C. et al. Silagens de girassol e de milho em dietas de vacas leiteiras: produção e composição do leite. Arquivo Brasileiro de Medicina Veterinária e Zootecnia, v.56, n.6, p.750-756, 2004.

SILVA, M.M.C.; RODRIGUES, M.T.; BRANCO, R.H. et al. Suplementação de lipídios em dietas para cabras em lactação: consumo e eficiência de utilização dos nutrientes. Revista Brasileira de Zootecnia, v.36, n.1, p.257-267, 2007.

SOUZA, R.P.N.; SILVA, R.S.S.F. Estudo de custo e rendimento do processamento de queijo Minas frescal. Ciências Tecnologia de Alimentos, v.25, n.1, p.170-174, 2005.

THOMAS, V.M.; MURRAY, G.A.; THACKER, D.L. et al. Sunflower silage in rations for lactating Holstein cows. Journal of Dairy Science, v.65, p.267, 1982.

ULBRICH, T.L.V.; SOUTHGATE, D.T.A. Coronary heart disease: seven dietary factors. Journal Lancet, v.338, n.19, p.985-992, 1991.

VALDEZ, F.R.; HARRISON, J.H.; FRANSEN, S.C. Effect of feeding corn-sunflower silagem on milk production, milk composition, and rumen fermentation of lactating dairy cows. Journal of Dairy Science, v.71, p.2462-2469, 1988.

VAN SOEST, P.J. Nutritional ecology of the ruminant. 2.ed. Ithaca: Cornell, 1994. 476p. 